IFN Working Paper No. 658, 2006

\title{
Is Team Formation Gender Neutral? Evidence from Coauthorship Patterns
}

Anne Boschini and Anna Sjögren 


\title{
Is team formation gender neutral? Evidence from coauthorship patterns*
}

\author{
Anne Boschini \\ Stockholm University \\ Anna Sjögren \\ IUI-The Research Institute of Industrial Economics
}

January 24, 2006

\begin{abstract}
We investigate if voluntary team formation is gender neutral. To this end, we model team formation as a random matching process influenced by the agents' preferences for team size and gender composition and derive how team formation depends on the gender ratio in the population of prospective team mates. We then test if the coauthorship pattern in articles published 1991-2002 in three top Economics journals is gender neutral, exploiting the variation in female presence across subfields of Economics. Our main finding is that gender sorting in coauthorship increases in the presence of women. In particular, we find that the gender gap in the propensity to coauthor with a woman increases in the presence of women in the subfield. We also find that women single author significantly more than men. These findings allow us to reject gender neutrality in team formation.
\end{abstract}

Keywords: Team formation, Gender sorting, Coauthorship patterns.

JEL: A14, J16, J41, M50.

*We thank the editor Cecilia Rouse, an anonymous referee, Jesper Roine and seminar participants at Stockholm and Uppsala University, SOFI and IUI for useful comments. We are also indebted to Edda Leitner for help with the AEA-directories. Assistance with data coding from Jakob Eliasson, Christina Håkansson, Gulay Özcar, and David Zimmerman is gratefully acknowledged. 


\section{Introduction}

Teamwork is a feature of many professional activities. Teamwork makes specialization possible and it also allows team members to join forces and take on projects too large for a single individual. Teamwork can therefore improve productivity. ${ }^{1}$ Both gains and costs of teamwork are linked to the heterogeneity of the team members. While the benefits of heterogeneity may depend on the nature of the activity as in Prat (2002), coordination costs are typically thought of as increasing in the heterogeneity of team members. One potentially important dimension of heterogeneity is gender. Recent experimental evidence in Ivanova-Stenzel and Kübler (2005), shows that the gender composition of teams affects team productivity and, in particular, they find that women perform worse in gender mixed teams.

Uncovering the influence of gender on team productivity and team formation is important for understanding the driving forces underlying gender differences in career choice and persistence in occupational gender segregation. ${ }^{2}$ Anyone considering the hard work required to reach top management positions, or to become a professor in Economics, needs to take into account the prospects of ever joining the board of directors or to find good coauthors. Whenever there is gender sorting in team formation, these prospects are smaller for the gender in minority.

The question asked in this paper is if gender plays a role in voluntary team formation. More specifically, we investigate empirically if the authorship pattern resulting from the voluntary team formation of academic economists is neutral with regard to gender. We address this question by developing a simple model of team formation of agents who have team size and gender preferences. We then test our theoretical predictions on the authorship pattern in articles published in three top journals of Economics, exploiting the variation in the presence of women across subfields of Economics. Our findings suggest that gender does matter for team formation.

The main contribution of this paper is to show that there is gender sorting in team formation in Economics at the subfield level. By modelling team formation of agents who have preferences over gender composition and team size, we derive implications of gender neutrality for how the gender gap in the propensity to form teams with women depends on the presence of women. This allows us to rule out that the gender sorting found in the data is an artefact of gender differences in field choice or preferences for teamwork. Using information on author publication records and affiliation, we can also exclude that the gender sorting found is the result of gender differences in seniority or gender sorting at the department level. Another interesting finding is that all-female teams are more likely to be long distance collaborations than gender mixed teams. This suggests that mixed teams are less likely to be formed when they have to take on the extra coordination costs associated with long distance collaboration, compared to all-female teams.

\footnotetext{
${ }^{1}$ Becker and Murphy (1992) show how the realization of the potential benefits of teamwork depends on the ability to coordinate the efforts of the team members. Benefits of teamwork also depend on the incentives for team members to contribute, as in e.g. Kendal and Lazear (1992).

${ }^{2}$ See e.g. Breen and García-Peñalosa (2002) for references on occupational gender segregation.
} 
We have chosen to study team formation in academia, and more specifically in Economics, which is one of many male dominated academic and professional fields. There are two reasons for this choice. First, team formation in academia is voluntary. Researchers team up only when all parties think they are better off collaborating than writing articles alone. Consequently, the teams formed are likely to reflect individual tastes and perceptions of the returns to collaboration, as well as the costs of coordination. Second, quantity and quality of output in academia are easily measured by publications in academic journals of different rank. This allows us to control for individual heterogeneity in productivity. We have limited the present study of authorship patterns to articles published in three general top Economics journals, the American Economic Review, the Journal of Political Economy, and the Quarterly Journal of Economics between 1991 and 2002. Apart from reducing the variation in the quality of research output, a further argument for selecting these journals is that they have been the focus of other recent studies of authorship patterns in Economics, notably Laband and Tollison (2000) and Hamermesh and Oster (2002).

Ferber and Teiman (1980) and McDowell and Kiholm Smith (1992), established early on that there is a pattern of gender sorting in coauthorships in Economics and that women write more single authored articles. In data from 1969 to 1986 on the publications of a sample of 178 Ph.D.'s from top20 US institutions, McDowell and Kiholm Smith (1992) found that women were over five times more likely than men to have female coauthors. Gender sorting as a reason for high rates of female single authorship, and for the difficulties of women to pursue careers in the Economics profession, is discussed by Ginther and Kahn (2004), Kahn (1995, 2002), and McDowell, Singell and Ziliac (1999, 2001).

A drawback of the earlier studies of gender sorting is that they do not rule out that gender sorting in coauthorship may result from gender sorting in the choice of subfields, or that high female single authorship may be the consequence of gender differences in preferences for teamwork or of differences in single authorship across subfields. The present study, as well as Dolado, Felgueroso and Almunia (2005), shows that there is, in fact, considerable gender segregation in the choice of subfields. We also find large variation across subfields in the prevalence of single authorship. ${ }^{3}$

The paper proceeds as follows. In Section 2, we develop a model of team formation where researchers have preferences over team size and gender composition. We generate a set of testable predictions for how the male and female propensities to coauthor with a woman and to single author depend on the fraction of women in the population of researchers. Next, we present our data on team formation in Economics and expose recent trends in authorship patterns. The aim is to investigate if the overall pattern in the data suggests gender sorting in team formation. We find that women are twice as likely as men to coauthor with women, but that gender differences in single authorship are minor. At the end of Section 3, we calibrate the model developed in Section 2 to fit the general authorship pattern. At most 80 percent the of researchers can have gender neutral preferences for the model to fit data. Section 4 formally tests the predictions

\footnotetext{
${ }^{3}$ This is also found in Hamermesh and Oster (2002).
} 
generated by the model. We estimate probit models of the probability to coauthor with a woman and the probability to single author, controlling for author, article, team, and field heterogeneity. We are able to reject that the authorship pattern in Economics is consistent with gender neutral preferences. Various robustness checks confirm the pattern of gender sorting in team formation. Section 5 concludes.

\section{A simple model of gender preferences in team formation}

Assume a population of equally able male and female researchers within a research field. The fraction of female researchers is exogenously given by $\phi$ and the male fraction is $1-\phi$. Researchers can work alone or do research in teams.

First, let $u_{i a}$ be the utility accruing to a researcher of gender $i$ of doing research in a team of type $a \in\{S, M, C\}$, where:

$$
\begin{aligned}
S & =\text { single authorship } \\
M & =\text { mixed coauthorship, i.e. a team with the opposite sex, } \\
C & =\text { single sex coauthorship, i.e. a team with the same sex }
\end{aligned}
$$

Second, let researchers rank these team types differently. We assume that the preferences over teamwork and gender are independent, but we allow for the possibility that preference distributions are gender specific. In order to focus on the issue of gender preferences, the model abstracts from team formation considerations that stem from differences in individual research ability, which drive team formation patterns in Goyal et al (2004). In the empirical analysis in Section 4 below, we will, however, control for observable individual differences in research productivity.

Let a fraction $\mu_{i}$ of gender $i$ always rank teamwork higher than working alone, while a fraction $\sigma_{i}$ always prefers single work. Let the remaining $\left(1-\sigma_{i}-\mu_{i}\right)=\kappa_{i}$ fraction of agents rank teamwork or single work higher depending on the sex of the prospective coauthor. Further, assume that a fraction $\nu_{i}$ (independent of $\sigma_{i}$ and $\mu_{i}$ ) of agents of gender $i$ be neutral regarding the gender of team mates, while the remainder $\left(1-\nu_{i}\right)$ has gendered preferences, i.e. prefers working in single sex teams to working in mixed teams. The joint distribution of gender and team size preferences for gender $i$, and the implied ranking of team types is given by Table 1 . 


\begin{tabular}{|c|c|c|c|}
\hline & & \multicolumn{2}{|c|}{ Gender Preference } \\
\hline \multirow{2}{*}{\multicolumn{2}{|c|}{$\begin{array}{l}\text { Team Size } \\
\text { Preference }\end{array}$}} & $\begin{array}{c}\text { Gendered } \\
1-\nu_{i}\end{array}$ & $\begin{array}{c}\text { Neutral } \\
\nu_{i}\end{array}$ \\
\hline & & & \\
\hline $\begin{array}{l}\text { Single } \\
\text { implied ranking }\end{array}$ & $\sigma_{i}$ & $\begin{array}{c}\sigma_{i}\left(1-\nu_{i}\right) \\
u_{i S}>u_{i U}\end{array}$ & $\begin{array}{c}\sigma_{i} \nu_{i} \\
u_{i S}>u_{i U}=u_{i H}\end{array}$ \\
\hline $\begin{array}{r}\text { Conditional } \\
\text { implied ranking }\end{array}$ & $\kappa_{i}$ & $\begin{array}{c}\kappa_{i}\left(1-\nu_{i}\right) \\
u_{i H}<u_{i S}<u_{i U}\end{array}$ & $\begin{array}{c}\kappa_{i} \nu_{i} \\
u_{i H}=u_{i S}=u_{i U}\end{array}$ \\
\hline $\begin{array}{l}\text { Multi } \\
\text { implied ranking }\end{array}$ & $\mu_{i}$ & $\begin{array}{c}\mu_{i}\left(1-\nu_{i}\right) \\
u_{i S}<u_{i H}\end{array}$ & $\begin{array}{c}\mu_{i} \\
u_{i S}<u_{i H}=u_{i U}\end{array}$ \\
\hline
\end{tabular}

Table 1: Joint distribution of gender and team size preferences and the implied ranking of team types.

We do not model explicitly why researchers differ in their rankings over teamwork and gender, but there may be both productivity concerns and pure taste underlying these rankings. Teamwork may be more or less rewarding depending on the agent's ability to realize the potential benefits of teamwork or the effort and enjoyment associated with working in teams. A possible source of gender difference in ranking of teamwork versus single authorship may stem from differences in responsibilities outside the workplace, that can render coordination with a coauthor more complex. As regards gender preferences, there may be real or perceived gender specific coordination costs that affect the quality of the output, or the effort required in producing it. Alternatively, as suggested in Ivanova-Stenzel and Kübler (2005), gender composition may affect team members willingness to contribute and to free ride. Furthermore, following the advice of Hamermesh (2004) to young female economists, if a researcher suspects that she will not be duly credited for her contribution to the output produced in a mixed team, she ought not to be part of such a team.

\subsection{Team formation and the distribution of articles by team type}

Each period agents are randomly matched in pairs. Each pair will form a team and jointly write two articles unless one or both agents strictly prefer working alone. In that case, they will write one paper each. Hence, output in number of articles per person is assumed to be constant across team types and per period. ${ }^{4}$ Given the distribution of preferences described above, we can derive the distribution of articles by team type. This matching process is mechanical in the sense that individual researchers do not act on their preference in order to affect the likelihood of finding a good match. One way

\footnotetext{
${ }^{4}$ In the Economics literature, the assumption of constant value of output per researcher across team sizes finds some support in the empirical findings of Sauer (1988) and McDowell and Kiholm Smith (1992).
} 
to look at it, is that by choosing to work within a specific field, where the distribution of preferences and gender composition are given, the individual has already maximized the likelihood of finding the preferred match. In other words, the matching process takes place within the agents' preferred field and results in a distribution of articles by team types.

The fraction of articles produced by female coauthorships is the product of the probability that two women are matched in a pair and the probability that none of them strictly prefers working alone to working with another woman:

$$
P\left(C_{f}\right)=\phi^{2}\left(1-\sigma_{f}\right)^{2} .
$$

Analogous reasoning applies throughout. Hence, the fraction of articles produced by male coauthorships is:

$$
P\left(C_{m}\right)=(1-\phi)^{2}\left(1-\sigma_{m}\right)^{2} .
$$

From (1) and (2) it is clear that the fraction of male and female coauthorships depend only on the fraction of women in the population and on the preference for single authorship, $\sigma_{i}$. The fraction of articles produced in mixed coauthorships is given by the probability of obtaining a gender mixed match times the probability that none of the researchers prefers writing alone either because they have preferences for single authorship or because they do not like working with the opposite sex:

$$
P(M)=2 \phi(1-\phi)\left(\mu_{f}+\kappa_{f} \nu_{f}\right)\left(\mu_{m}+\kappa_{m} \nu_{m}\right) .
$$

Male and female single authors are all those who got matched to the same sex, where either of the two potential team mates did not want to coauthor, plus those who got teamed up with someone of the opposite sex and found that at least one of them did not want to coauthor or had preferences against the opposite sex: ${ }^{5}$

$$
P\left(S_{f}\right)=\phi^{2}\left(1-\left(1-\sigma_{f}\right)^{2}\right)+\phi(1-\phi)\left(1-\left(\mu_{f}+\kappa_{f} \nu_{f}\right)\left(\mu_{m}+\kappa_{m} \nu_{m}\right)\right)
$$

and

$$
P\left(S_{m}\right)=(1-\phi)^{2}\left(1-\left(1-\sigma_{m}\right)^{2}\right)+\phi(1-\phi)\left(1-\left(\mu_{f}+\kappa_{f} \nu_{f}\right)\left(\mu_{m}+\kappa_{m} \nu_{m}\right)\right) .
$$

\subsection{Implications for differences in male and female authorship patterns}

The next step is to investigate how male and female authorship patterns depend on the fraction of women present in the research field under different assumptions regarding the importance of gender preferences, $\nu_{i}$. The propensity to coauthor with a women,

\footnotetext{
${ }^{5}$ It is easily verified that the total share of articles attributed to female authors is indeed $\phi$, $P\left(S_{f}\right)+P\left(T_{f}\right)+\frac{1}{2} P(M)=\phi$.
} 
that is the conditional probability to have a female team mate (FTM), is:

$$
\begin{aligned}
& P(F T M \quad \mid m)=\frac{P(M)}{2(1-\phi)}=\left(\mu_{f}+\kappa_{f} \nu_{f}\right)\left(\mu_{m}+\kappa_{m} \nu_{m}\right) \phi \\
& P(F T M \quad \mid f)=\frac{P\left(C_{f}\right)}{\phi}=\left(1-\sigma_{f}\right)^{2} \phi
\end{aligned}
$$

for men and women respectively.

It is clear from (6) and (7) that the male and female propensities to coauthor with a woman are linear and increasing in the fraction of women, $\phi$. Moreover, while the male propensity to coauthor with a woman decreases with the fraction of agents of either sex who have gender biased preferences, the female propensity to coauthor with a woman is independent of gender preferences since, by assumption, there are no agents who have a preference against their own gender.

We now turn to the propensities to single author. These can be written as:

$$
\begin{array}{ll}
P(S \quad \mid \quad m)=\frac{P\left(S_{m}\right)}{(1-\phi)}= \\
\quad \sigma_{m}\left(2-\sigma_{m}\right)+\left(\left(1-\sigma_{m}\right)^{2}-\left(\mu_{f}+\kappa_{f} \nu_{f}\right)\left(\mu_{m}+\kappa_{m} \nu_{m}\right)\right) \phi \\
P(S \quad \mid \quad f)=\frac{P\left(S_{f}\right)}{(\phi)}= \\
& \left(1-\left(\mu_{f}+\kappa_{f} \nu_{f}\right)\left(\mu_{m}+\kappa_{m} \nu_{m}\right)\right)+\left(\left(\mu_{f}+\kappa_{f} \nu_{f}\right)\left(\mu_{m}+\kappa_{m} \nu_{m}\right)-\left(1-\sigma_{f}\right)^{2}\right) \phi .
\end{array}
$$

Also the propensities to single author are linear in the presence of women, $\phi$. Expressions (6), (7), (8), and (9) can therefore be summarized as follows:

$$
\begin{array}{r|l}
P(F T M & i)=\beta_{i}^{F T M} \phi \\
P(S & i)=\alpha_{i}+\beta_{i}^{S} \phi
\end{array}
$$

where $\beta_{i}^{F T M}, \alpha_{i}$, and $\beta_{i}^{S}$ depend on the parameters of the model.

Next, we analyze the implications of alternative hypotheses regarding the distributions of preferences of male and female researchers for (6), (7), (8), and (9). We formulate two hypotheses; (i) gender irrelevance and (ii) gender neutrality. The first, states that gender is irrelevant and that there is one population of gender neutral agents who are all drawn from the same distribution of team size preferences. The second hypothesis is less strong in the sense that there may be systematic gender differences in team size preferences even if gender preferences per se are neutral.

Proposition 1 (Gender irrelevance) If $\sigma_{f}=\sigma_{m}=\sigma, \mu_{f}=\mu_{m}=\mu$, and $\nu_{f}=$ $\nu_{m}=1$, gender is irrelevant for team formation and $\beta_{f}^{F T M}=\beta_{m}^{F T M}, \alpha_{f}=\alpha_{m}$, and $\beta_{f}^{S}=\beta_{m}^{S}=0$.

Proof See Appendix A.1.

When researchers are gender neutral and male and female researchers share the same team preferences, gender is irrelevant for the authorship pattern. Hence, single 
authorship is obviously the same for men and women and insensitive to the fraction of female researchers. The propensity to form a team with a women will also be the same for men and women: There is no gender gap.

Proposition 2 (Gender neutrality) If $\sigma_{f} \neq \sigma_{m}$ and $\nu_{f}=\nu_{m}=1$, then $\sigma_{m} \gtreqless \sigma_{f}$ implies that $\beta_{m}^{F T M} \lesseqgtr \beta_{f}^{F T M}, \alpha_{m} \gtreqless \alpha_{f}$, and $\beta_{m}^{S \lesseqgtr} \beta_{f}^{S}$.

Proof See Appendix A.1.

Allowing for gender differences in team preferences, our model suggests that the qualitative implications of gender neutrality hinge on which gender has the strongest preferences for single authorship, that is if $\alpha_{m} \gtreqless \alpha_{f}$. It is also clear that gender neutrality is reconcilable with a gender gap in the propensity to coauthor with a woman. In particular if, as was found in previous empirical studies, female researchers have a higher propensity to coauthor with women than male researchers, i.e. $\beta_{m}^{F T M}<\beta_{f}^{F T M}$, Proposition 2 shows that preferences still can be gender neutral if male researchers single author more than female researchers. ${ }^{6}$ Figure 1 shows how the fraction of women, $\phi$, affects the male and female propensities to single author and to coauthor with a woman under the assumptions that preferences are gender neutral, but the fraction of male researchers who prefers to work alone is larger than the fraction of female researchers who prefer single work. ${ }^{7}$

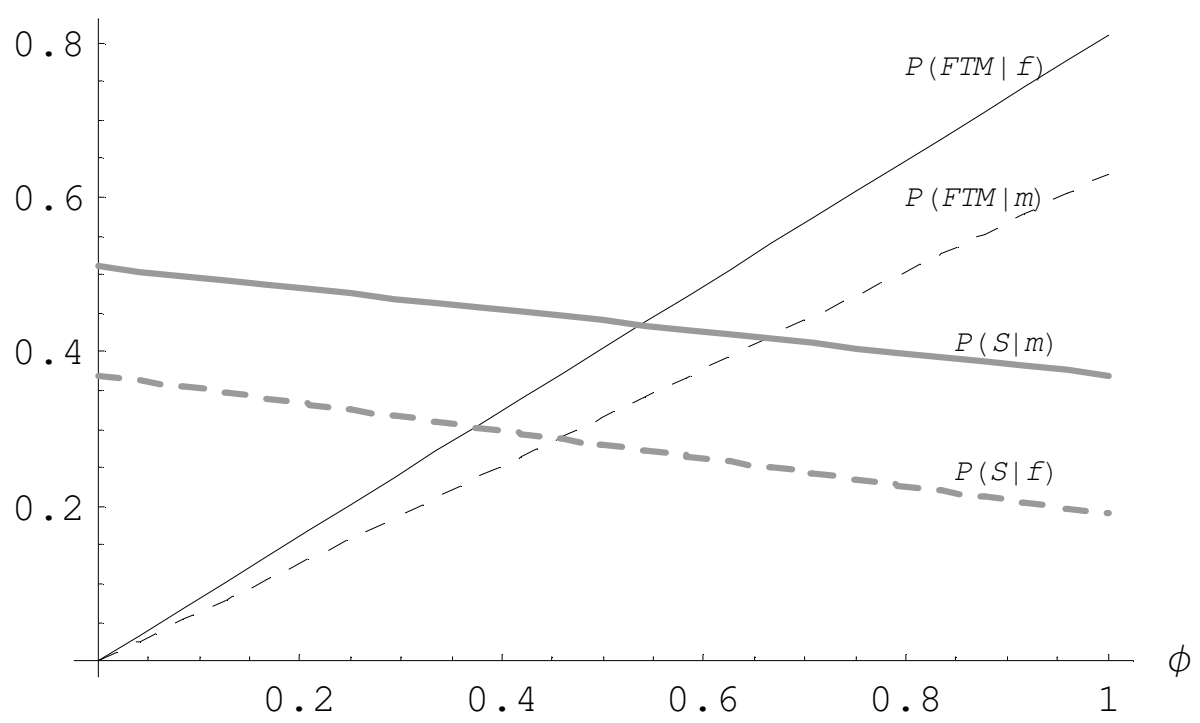

Figure 1: Gender neutrality, $\sigma_{m}>\sigma_{f}$

\footnotetext{
${ }^{6}$ Recall, however, that Ferber and Teiman (1980) and McDowell and Kiholm Smith (1992) found that women wrote more single authored papers.

${ }^{7}$ The parameter values used in Figure 1 are: $\nu_{f}=\nu_{m}=1, \sigma_{f}=0.1, \sigma_{m}=0.3$ and $\mu_{f}=\mu_{m}=0.2$.
} 


\section{Team formation in Economics}

This section presents data on the authorship pattern Economics 1991-2002 from three different sources, EconLit, JSTOR, and the American Economic Association membership directories. We report trends in team formation in relation to the findings of the previous literature. In particular, we focus on the gender sorting in coauthorships within subfields of Economics. We also calibrate the model developed in Section 2 to fit the overall authorship pattern.

\subsection{The data}

The data set covers the 4040 articles published in the American Economic Review (AER), the Journal of Political Economy (JPE) and the Quarterly Journal of Economics (QJE) during the period from 1991 to 2002 and is collected mainly from EconLit. ${ }^{8}$ The American Economic Review has by far the most entries and accounts for almost two thirds of all articles. There are no significant differences between the journals, except that AER published shorter articles on average than the other two journals. ${ }^{9}$ We have gender coded all the authors of each article. Excluding the 50 articles where we were unable to identify the sex of at least one of the contributing authors, we have a data set consisting of 3090 articles written by in total 5308 authors. Our data set, which will be referred to as the Top 3 journal data set (T3), contains gender and affiliation of authors, as well as JEL-codes, the number of pages, print year, and source (journal) of each article.

In order to investigate how the authorship pattern depends on the fraction of women in the relevant pool of prospective collaborators, we make use of the JEL-codes provided by EconLit to classify the articles into major fields. The idea is that authors writing in a particular field belong to the same subpopulation of economists. However, articles typically have more than one JEL-code and, hence, belong to more than one field. We count an article with two JEL-codes in both fields. The average number of JEL-codes per article is 1.44. The nine most frequent JEL-codes account for more than five per cent of the articles in each year of our sample period. ${ }^{10}$

For these nine major fields we have constructed a measure of the fraction women in the field by computing the fraction of articles contributed by female authors. We have also computed a measure of the relative field size. In order to obtain an independent measure of the relative sizes of JEL-fields, our T3-dataset is complemented with JEL-code information from all the journal articles available in EconLit each year of our sample period. Since authors in EconLit are not gender coded, we have used

\footnotetext{
${ }^{8}$ For 2002, the last numbers of the AER, JPE and QJE are not in the sample. 1991 is the first year in our sample due to the reform of the JEL classification that occurred that year. To avoid misclassifications we have not attempted to recode the JEL-classifications for articles published in 1990 and earlier.

${ }^{9}$ One reason is that the AER has more text per page, another is that articles in the AER May number (Papers and Proceedings of the American Economic Association meetings) are shorter than average. We control for this in various ways in the econometric analysis of Section 4 .

${ }^{10}$ In no single year does any of the other JEL-codes rank higher than the top nine.
} 
the American Economic Association membership directories for 1993, 1997 and 2002 to construct independent measures of the fraction of female researchers in each major JEL-field. (See Appendices C and D for detailed descriptions of the data from EconLit and from the AEA directories.) We believe the AEA directories are reasonably representative for the population of researchers publishing in these top journals, since a very large fraction of the authors in our sample are affiliated to American universities and because many of the non-American researchers who publish in top journals are members of the AEA. Table 2 summarizes the information on relative sizes and fraction of women by JEL-fields. Note, that the major fields are relatively overrepresented in our sample, compared to all journals in the EconLit, but also that the figures for share of women by field obtained from the AEA directories are very similar in magnitude to the figures computed from our sample. ${ }^{11}$

\begin{tabular}{|c|c|c|c|c|c|}
\hline \multirow[b]{2}{*}{ JEL codes } & \multicolumn{2}{|c|}{ relative field size $(\%)$} & \multicolumn{2}{|c|}{$\begin{array}{c}\text { Female share of researchers, } \\
\Phi(\%)\end{array}$} & \multirow{2}{*}{$\begin{array}{c}\begin{array}{c}\text { Single authorships } \\
(\%)\end{array} \\
\text { our sample }\end{array}$} \\
\hline & our sample & EconLit & our sample & AEA & \\
\hline D - Microeconomics & 19.4 & 7.3 & 9.6 & 12.9 & 41.0 \\
\hline E-Macroeconomics & 11.2 & 6.0 & 7.5 & 9.3 & 42.4 \\
\hline F - International economics & 7.5 & 6.5 & 11.6 & 13.5 & 47.2 \\
\hline G - Finance & 7.4 & 6.9 & 9.5 & 9.0 & 27.4 \\
\hline H - Public economics & 6.7 & 3.6 & 10.0 & 13.1 & 42.7 \\
\hline I - Health & 5.8 & 3.4 & 21.4 & 23.1 & 44.2 \\
\hline $\mathrm{J}$ - Labor economics & 15.7 & 6.5 & 19.4 & 20.6 & 41.3 \\
\hline L - Industrial organization & 8.3 & 6.8 & 14.1 & 12.6 & 36.8 \\
\hline O - Development & 10.1 & 8.2 & 12.0 & 12.2 & 41.2 \\
\hline Other & 8.0 & 46.1 & 12.8 & 11.4 & 54.2 \\
\hline All & 100 & 100 & 12.6 & 15.7 & 41.7 \\
\hline
\end{tabular}

Table 2: JEL-code descriptives

EconLit does not provide any author information other than affiliation at the time of publication. In order to rule out that any gender sorting in coauthorship patterns detected in our data is due to productivity differences and seniority, we have independently collected data on the publication records of all the authors in our T3-sample. Using JSTOR we have counted each author's number of publications in Top 5 journals between 1950 and the year of publication in our sample, as well as noted the year of the authors' first Top 5 publication. ${ }^{12}$

\footnotetext{
${ }^{11}$ When computing these figures for the T3-data set, male and female appearances in the data have been weighted by the number of contributing authors of each article.

${ }^{12}$ Top 5 journals include AER, JPE and QJE, Econometrica and the Review of Economic Studies. The reason for widening the sample of journals is to get as good a measure as possible of the authors top-quality publication record.
} 
With a total of 5308 authors of 3090 articles, the average team size in our data is 1.72 authors. There are 2909 individual researchers in our sample. Two thirds of authors appear only once in our data, and only 5 percent of the authors have more than five publications. Hence, it is fair to say that the publication pattern in our data is not driven by the behavior of a small number of very successful economists, but rather by authors that appear at most twice.

\subsection{Authorship patterns in Economics}

Over the period 1991-2002, women have contributed on average 13 percent of the articles in the top three journals. ${ }^{13}$ Table 3 reports the distribution of articles by team size and gender of the first author of the article. It is worth noting that there is no time trend in the overall contribution of women. This can be compared to a female share of faculty of 15 per cent at U.S. Ph.D. granting departments in 2000 according to the Annual Reports of the American Economic Association Committee on the Status of Women in the Economics Profession. ${ }^{14}$ Another striking feature is that there are only minor gender differences in the overall pattern of authorship. Table 3 reports that for the period as a whole, women are slightly underrepresented in coauthorships with more than two authors compared to men (10.3 vs 13.3 percent). The data also reveal that there is a decline in single authorships, in particular for women. Towards the latter half of our period of study, single authorship of men is slightly, although insignificantly, higher than that of women such that over the period as a whole, there are only minor gender differences.

Table 3 confirms the increasing trend in coauthorships observed by others. For example, Hamermesh and Oster (2002) report an average share of coauthored articles of only 30 percent during the 1970s in the AER, the JPE and the QJE. Coauthored articles make up 56 percent of our sample.

\footnotetext{
${ }^{13} 12.9$ per cent of the 3090 articles have female first authors. If all 5308 authors are considered, 11.8 per cent are women. If the contribution of women to each article is weighted by the number of authors, as in Table 2, the female share is 12.6 per cent.

${ }^{14}$ Excluding untenured faculty, in the figure drops to 10 percent, which is still a doubling since 1976. Restricting the sample to the Top20 departments puts the female share in 2000 at 8 percent (tenured faculty) and 13 (untenured included).
} 


\begin{tabular}{|c|c|c|c|c|c|c|c|c|c|}
\hline \multirow[b]{2}{*}{ Team size } & \multicolumn{3}{|c|}{$\begin{array}{c}1991-1996 \\
\text { Gender of first author }\end{array}$} & \multicolumn{3}{|c|}{$\begin{array}{c}1997-2002 \\
\text { Gender of first author }\end{array}$} & \multicolumn{3}{|c|}{$\begin{array}{c}\text { 1991-2002 } \\
\text { Gender of first author }\end{array}$} \\
\hline & female & male & all articles & female & male & all articles & female & male & $\overline{\text { all articles }}$ \\
\hline$\overline{\text { Single }}$ & 111 & 676 & 787 & 66 & 493 & 559 & 177 & 1169 & 1346 \\
\hline row $\%$ & 14.1 & 85.9 & 100 & 11.8 & 88.2 & 100 & 13.2 & 86.9 & 100 \\
\hline column $\%$ & 52.9 & $47.5^{*}$ & 48.2 & 35.1 & 38.9 & 38.4 & 44.5 & 43.4 & 43.6 \\
\hline Double & 82 & 596 & 678 & 98 & 570 & 668 & 180 & 1166 & 1346 \\
\hline row $\%$ & 12.1 & 87.9 & 100 & 14.7 & 85.3 & 100 & 13.4 & 86.6 & 100 \\
\hline column \% & 39.1 & 41.9 & 41.5 & 52.1 & $44.9 * *$ & 45.9 & 45.2 & 43.3 & 43.6 \\
\hline Multiple & 17 & 151 & 168 & 24 & 206 & 230 & 41 & 357 & 398 \\
\hline row $\%$ & 10.1 & 89.9 & 100 & 10.4 & 89.6 & 100 & 10.3 & 89.7 & 100 \\
\hline column $\%$ & 8.1 & 10.6 & 10.3 & 12.8 & 16.2 & 15.8 & 10.3 & $13.3^{*}$ & 12.9 \\
\hline all articles & 210 & 1423 & 1633 & 188 & 1269 & 1457 & 398 & 2692 & 3090 \\
\hline row $\%$ & 12.9 & 87.1 & 100 & 12.9 & 87.1 & 100 & 12.9 & 87.1 & 100 \\
\hline column \% & 100 & 100 & 100 & 100 & 100 & 100 & 100 & 100 & 100 \\
\hline
\end{tabular}

Table 3: Distribution of articles by team size and gender of first author

Turning to the issue of gender sorting, McDowell and Kiholm Smith (1992) found that women were five times more likely than men to have a female coauthor. In our data women are slightly more than twice as likely as men to have a female coauthor. Of the male team workers in or sample, 12.9 percent have at least one female coauthor. The corresponding figure for women is 28.4 percent. ${ }^{15}$ Although the gender gap in the propensity to coauthor with a woman is nowhere near as large as during the 1980s, there still is a gap. However, a gap does not need to imply gender sorting in team formation. First, it is possible that the apparent gender sorting in coauthorships is a consequence of male and female sorting into different fields of Economics rather than a consequence of biased gender preferences. As was shown in the theoretical model, it is also possible that the gender gap in the propensity to coauthor with a woman is driven by differences in the preference for teamwork.

Table 2 in the previous subsection revealed large differences the presence of women across fields. Female presence is roughly three times higher in Health than in Macroeconomics. There are also large differences in the prevalence of single authorship across fields of Economics. While only 28 percent of the Finance articles are single authored, almost half of the International Economics articles have only one author. In the minor fields, that constitute the Other category, as many as 57 percent of all articles are single authored. These variations across fields a likely to reflect field differences in the costs and benefits of teamwork. In the case of minor fields, the reason for single authorship may also be the result of the difficulty to find suitable coauthors in a smaller population.

\footnotetext{
${ }^{15}$ In a t-test, the gender difference in propensity to coauthor with a woman is statistically significant at the 99 percent level.
} 


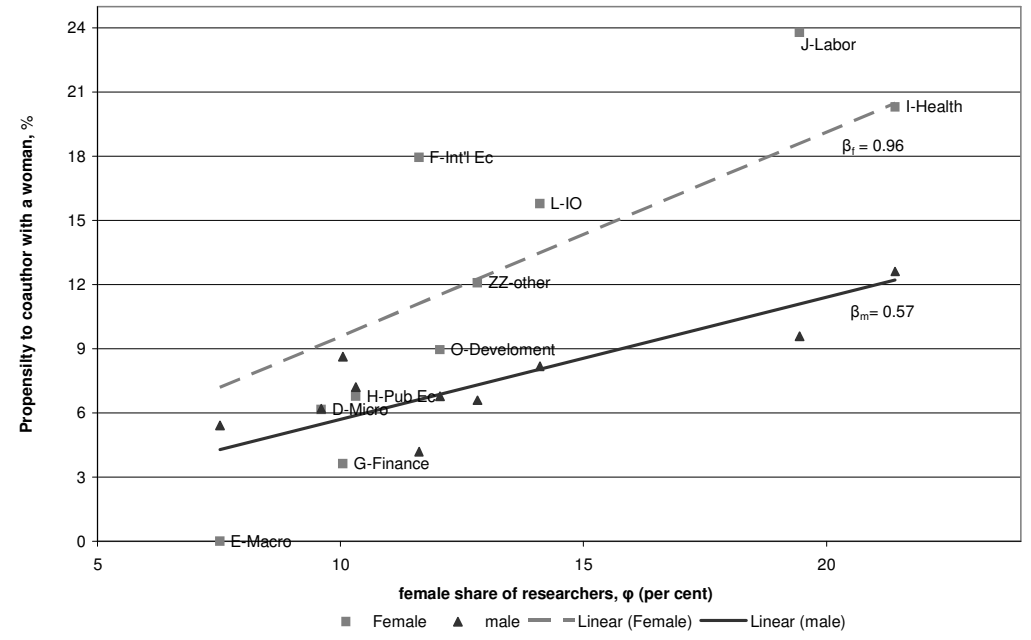

Figure 2: Female share of researchers by field and the propensity to coauthor with a woman

How does the gender gap in the propensity to coauthor with a woman relate to the presence of women economists in a field? Figure 2 reveals that the higher the share of female researchers in a field, the larger is the difference between female and male coauthorships patterns. As the fraction of female researchers increases, women tend to increasingly write with other women. Also the male propensity to coauthor with a woman is higher in fields with more women, but it increases less than that of women.

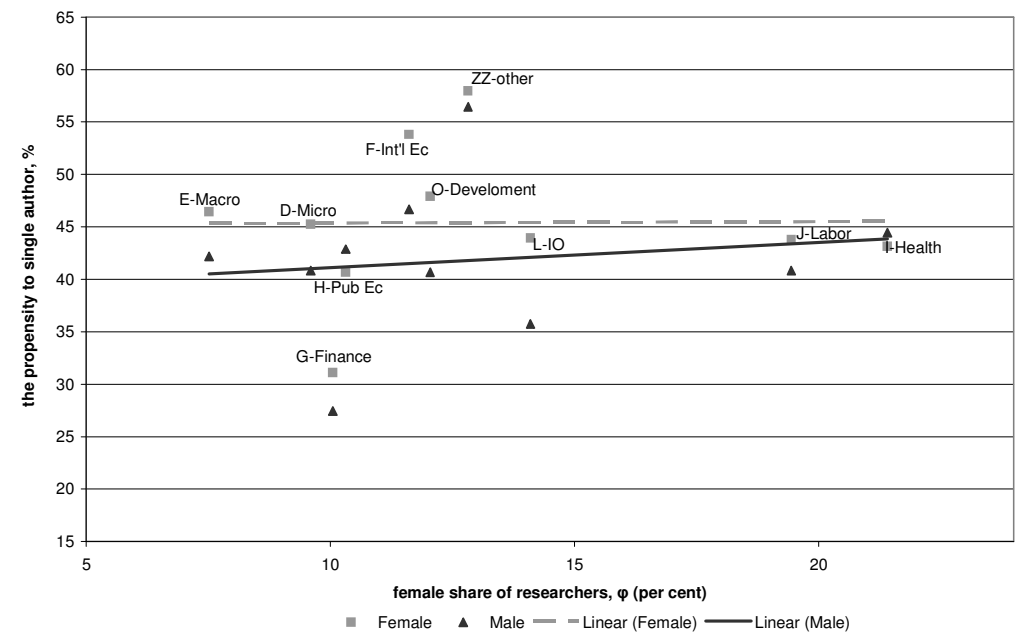

Figure 3: The propensity to single author

This first look at the data suggests that gender is not irrelevant. But the gender gap could be the result of differences in the prevalence of single authorship across fields 
and in team preferences. Figure 3, however, shows that both male and female single authorships are uncorrelated with the presence of female researchers. It is worth noting that only in Health and in Public Economics do women single author less than men.

Comparing Figures 2 and 3 to Figure 1, which was generated by the model, indicates that, the empirical pattern found could be the result of gender sorting if the heterogeneity of articles, authors, and teams can account for the lack if fit in the propensity to single author. Articles and authors in our sample are heterogeneous for a number of reasons. Although our narrow choice of journals controls to some extent for quality, some articles in our sample are part of conference volumes and some are from the AEA Papers and Proceedings. Furthermore, authors differ in seniority and publication record and they are affiliated to very different institutions. Some authors always write with the same coauthors, some teams are local, others long distance. We cannot rule out that the gender sorting in our data is a result of systematic gender differences in any of these dimensions. Before turning to formal testing of gender neutrality, we will take a look at some of these potential sources of gender sorting that are not related to gender preferences.

\subsection{Other potential sources of gender sorting}

\begin{tabular}{|c|c|c|c|}
\hline & \multicolumn{3}{|c|}{ Gender of author } \\
\hline & female & male & all authors \\
\hline \multicolumn{4}{|l|}{ affiliation } \\
\hline Top 3 & 68 & 833 & 901 \\
\hline row $\%$ & $7.6^{* * * *}$ & 92.5 & 100.0 \\
\hline column $\%$ & 10.8 & 17.8 & 17.0 \\
\hline Top 4-20 & 189 & 1356 & 1545 \\
\hline row $\%$ & 12.2 & 87.8 & 100.0 \\
\hline column $\%$ & 30.1 & 29.0 & 29.1 \\
\hline Other & 371 & 2491 & 2862 \\
\hline row $\%$ & 13.0 & 87.0 & 100.0 \\
\hline column $\%$ & 59.1 & 53.2 & 53.9 \\
\hline All affiliations & 628 & 4680 & 5308 \\
\hline row \% & 11.8 & 88.2 & 100.0 \\
\hline column $\%$ & 100.0 & 100.0 & 100.0 \\
\hline
\end{tabular}

*** statistically different compared to lower ranked affiliations at 99\%-level

Table 4: Authors by affiliation and gender.

According to Kahn (1995), authors' affiliation is the most important determinant of differences in men's and women's publication records. The researchers in our data are affiliated to 459 different institutions. If we rank the affiliations by how often they 
appear in our data, half of the 5308 authors are affiliated to the top 20 institutions, and one fifth to the top three, namely Harvard University, MIT and University of Chicago. Table 4 shows that women are underrepresented at the top compared to their overall representation. It is, hence, possible that some of the gender sorting in coauthorships is due to the absence of women at some of the top ranked departments rather than to gender preferences per se.

Another possible reason for the apparent gender sorting may be that men and women differ with regard to age and seniority, in particular if authors prefer to team up with coauthors of similar age and publication record. On average, the female authors in our sample have published four articles less than men. ${ }^{16}$ The female authors are also younger, at least as measured by the year of their first publication in top 5 journals, which is on average six years more recent than the average for men. It is notable that these gaps do not decline over time. If anything the gender gaps in number of publications and year of first publication grow over our period of analysis, largely because the male authors grow older and accumulate more publications. ${ }^{17}$ Table 5 shows the fraction female authors, and the ratio of female to male publication record, given the year of the author's first top 5 publication. For the most recent cohort, who got their first top 5 publication between 1997 and 2002, women make up 20 percent of the authors and the publication gap is virtually zero. In the earlier cohorts, there are fewer women and the publication gap is wider the further back we go.

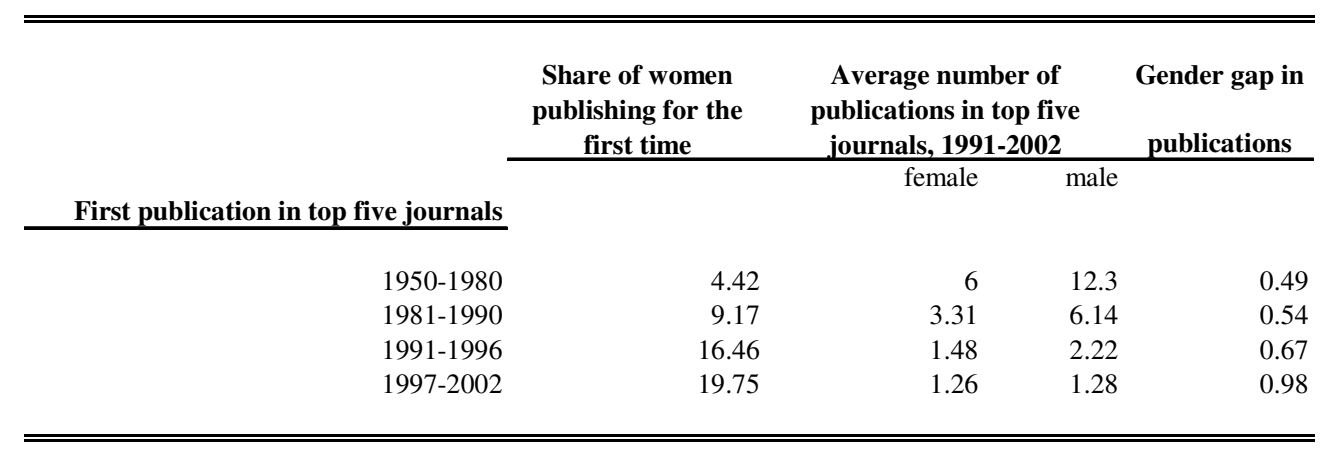

Table 5: Publications across cohorts of authors

Since the gender gap is almost closed for the most recent cohorts of economists, it is possible that gender differences in publications is a passing phenomenon. It could, however, be the case that women economists are as successful as men in publishing their dissertations, but that they subsequently leave academia or become less productive than men later on in their careers. Taking a look at the cohort of authors who published their first top 5 article during 1991-1996, shows that the ratio of female to male publications

\footnotetext{
${ }^{16}$ This result is driven by the fact that the 5 percent of the authors having at least five publications each are almost exclusively men, and that they on average have 13 publications. The maximum number of publications of a single author is 65 publications.

${ }^{17}$ There is no clear time trend in these seniority measures for the female authors.
} 
during the period 1991 and 1996 is 83 percent. In the subsequent five year period, the publication ratio is only 34 percent. This suggests that, women are almost as successful as men early on in their careers, but they do not keep up.

Another aspect of concern is that of local versus long distance coauthoring. As shown in Hamermesh and Oster (2002), there has been an increase in long distance coauthorships. The internet, they argue, has reduced the coordination costs associated with long distance teamwork. Hence, although nearby colleagues make up the most relevant pool of potential coauthors, geography is less restrictive now than it used to be. In our data, local teams account for 20 percent of all articles, but it is worth pointing out that gender mixed coauthorships are significantly underrepresented among the long distance teams. Not surprising, given the small fraction of women at each department, is that all-female coauthorships tend to be less local than all-male coauthorships. ${ }^{18}$

As discussed in Section 3.1, a fifth of the authors in our sample are part of team constellations that appear more than once in our data. There is no statistically significant difference between all-female and all-male coauthorships in this respect, but it is interesting to note that gender mixed teams are significantly underrepresented among the recurrent teams.

Considering the above indicated gender differences in female presence across fields of Economics, affiliation, publications and team characteristics, as well as the field differences and time trends in single authorship, we cannot yet rule out that the gender sorting in coauthorship patterns is consistent with gender neutral preferences.

\subsection{Calibrating the model to the authorship pattern in Eco- nomics}

Before we turn to formally test if the apparent gender sorting in team formation can be explained by differences in seniority, field choice or affiliation, we will take a look at how the overall pattern can be captured by the model. We explore two routes. First we consider how large a gap in the propensity to coauthor with a woman can be consistent with the levels of single authorship found, and (i) gender irrelevance, and (ii) gender neutrality. Second, we turn the question around and look for parameter values that can generate a gender gap in the propensity to coauthor with a woman of the observed magnitude of two, at the same time as it generates the correct levels of single authorship.

We use the following figures derived from our T3-sample for the calibration. The fraction of female researchers, $\phi$, is 12.9 percent; male single authorship constitute 43 percent of all male authorships, $P(S \mid m)=0.43$; and female single authorship is set at 44.5 percent, $P(S \mid f)=0.445$. The gap in the propensity to coauthor with a woman equals two, $P(F T M \mid f) / P(F T M \mid m)=2$. We assume that the fractions of men and women that always prefer working in teams, $\mu_{f}$ and $\mu_{m}$, are the same. ${ }^{19}$

\footnotetext{
1873.7 percent of female coauthorships are local versus 67.7 percent of male coauthorships. This difference is not statistically significant: a t-test of the difference yields $\mathrm{P}>|\mathrm{t}|=0.126$.

${ }^{19}$ In the first two simulations we assume $\mu=0.2$.
} 
First, what level of the gender gap in the propensity to coauthor with a woman is consistent with a level of single authorship of 43 percent when (i) gender is irrelevant? ${ }^{20}$ The solution is that 24.5 percent of both men and women should always prefer to single author and that there by assumption is a zero-gender gap in the probability to coauthor with a woman. This scenario is clearly not compatible with empirical patterns. (ii) What level of the gender gap in the propensity to coauthor with a woman is consistent with the observed gender specific levels of single authorship, $P(S \mid m)=0.43$, and $P(S \mid f)=0.445$, if preferences are gender neutral ${ }^{21}$ The calibration gives a gender gap in the propensity to coauthor with a woman of 95 percent, i.e. that the female propensity to coauthor with women is smaller than the male propensity to do so. ${ }^{22}$ Again, this is not compatible with what we observe.

Second, since gender neutral preferences cannot generate a gender gap of the correct magnitude, we explore how large the fractions of male and female researchers that have gendered preferences need to be in order to reconcile the gender gap in the propensity to coauthor with a woman with the observed magnitudes of single authorship. ${ }^{23}$ Figure 4, illustrates the results. The fraction of neutral women, $\nu_{f}$, is on the horizontal axis, while the fraction of neutral men, $\nu_{m}$, is on the vertical axis. The downward sloping functions $\nu_{m}\left(\nu_{f} ; \mu\right)$ depict the fraction of neutral men as a function of the share of neutral women for different levels of the fraction of researchers who always prefer working in teams, $\mu{ }^{24}$ The highest locus corresponds to $\mu=0$, i.e. the fraction of researchers who always prefer coauthorship is zero, and shows the highest combinations of neutral male and female researchers consistent with a gender gap of two. When $\mu=0$, and there are as many gender neutral male as female researchers, at least 20 percent of the researchers need to have gendered preferences to generate a gender gap of the correct magnitude. If only either men or women have gendered preferences, the largest fraction of neutral agents, consistent with a gender gap of two, is 65 percent. The lowest locus depicted, corresponds to $\mu=0.6$.

It is clear that the higher is the fraction of researchers who always prefer coauthorship, $\mu$, the more gendered need preferences be for there to be a gender gap of the correct magnitude. It is also evident from Figure 4 that there is a negative relation between male and female gender preferences. Hence, our model cannot tell us whether the observed gap is generated by male or female gender preferences.

\footnotetext{
${ }^{20}$ This corresponds to assuming that $\nu_{f}=\nu_{m}=1$, and that $\sigma_{f}=\sigma_{m}=\sigma . P(S)$ is set to 0.43 irrespective of gender and $\mu=0.2$.

${ }^{21}$ This corresponds to assuming that $\nu_{f}=\nu_{m}=1$ and $\sigma_{f} \neq \sigma_{m}$. Again, we assume $\mu=0.2$.

${ }^{22}$ More specifically, the calibration gives $\sigma_{m}=0.236$ and $\sigma_{f}=0.276$, and implies that $P(F T M \mid$ $m)=0.066$ and $P(F T M \mid f)=0.063$ and, hence that $P(F T M \mid f) / P(F T M \mid m)=0.95$.

${ }^{23}$ First we solve $P(F T M \mid f) / P(F T M \mid m)=2$ for the fraction of neutral men $\nu_{m}$ as a function of the other parameters. We then use this to solve for a level of $\sigma_{m}$ consistent with the overall level of single authorship, $P(S)=0.43$. Finally we solve for the $\sigma_{f}$ consistent with $P(S \mid f)=0.445$. This gives us the solution $\sigma_{f}=0.0085, \sigma_{m}=0.236$ and $\nu_{m}\left(\nu_{f} ; \mu\right)$ as depicted in Figure 4.

${ }^{24} \mu=\{0,0.1,0.2,0.3,0.4,0.5,0.6\}$ in Figure 4.
} 


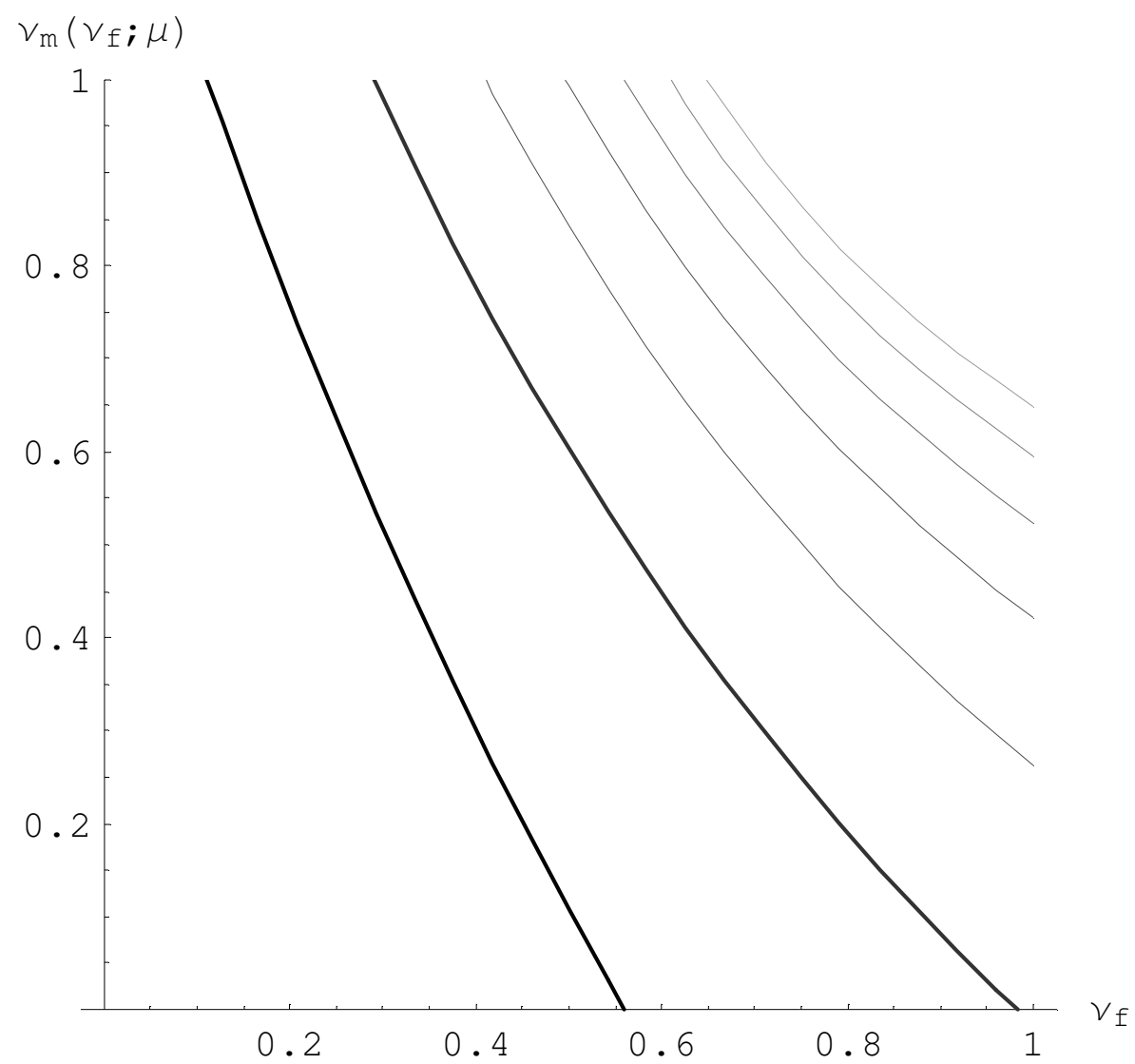

Figure 4: Gender preferences consistent with a gender gap of two

\section{Testing gender neutrality}

We formally test whether the pattern of authorship in articles published in the American Economic Review, the Journal of Political Economy and the Quarterly Journal of Economics between 1991 and 2002 can be the outcome of gender neutral team formation at the field level, controlling for author, article, team and field heterogeneity.

We take the implications of the model developed in Section 2 to the data by estimating the following two equations. The first equation is the probability that author $i$, of an article in field $j$ coauthors with a woman:

$$
P(F T M)_{i j}=\alpha_{1}^{F T M} f_{i}+\beta_{2}^{F T M} \phi_{j}+\beta_{3}^{F T M} f_{i} \phi_{j}+X_{i j}^{\prime} \gamma+\varepsilon_{i},
$$

where $F T M$ stands for female team mate, $f_{i}$ is an indicator variable taking value one if author $i$ is female, $\phi_{j}$ is the fraction of women in field $j$, and $X$ is a vector of author, article, team, and field controls. The second equation specifies the probability of single authorship, $S$, of author $i$ in field $j$ and contains the same main explanatory variables as equation (10) with minor differences regarding the set of controls, $Z$. 


$$
P(S)_{i j}=\alpha_{1}^{S}+\alpha_{2}^{S} f_{i}+\beta_{3}^{S} \phi_{j}+\beta_{4}^{S} f_{i} \phi_{j}+Z_{i j}^{\prime} \xi+\epsilon_{i} .
$$

The sets of control variables, $X$ and $Z$, attempt to capture the various dimensions of heterogeneity in our sample. Author specific controls capture individual characteristics of the author, such as publication record and academic affiliation. Team specific controls capture aspects of the team, i.e. if the team is local and/or recurrent as well as differences in seniority among the team members. Field specific controls aim at capturing technological differences across fields, e.g. prevalence of single authorship. Article specific controls include dummy variables for the different journals, year of publication, and number of pages. We allow for several interaction effects between the control variables and female, in order to capture any potential gender differences in these other dimensions of the sample.

\subsection{Variable construction}

We treat the 3090 articles in our sample as independent observations. The characteristics of the first author of the article are used as author specific controls. Hence, we use the alphabet and family names as the randomizing device which draws the first author as a "representative" author of the article. ${ }^{25}$

The dependent variable of equation (10) is the binary variable female team mate. It takes the value one if at least one of the coauthors (first author excluded) of the article in question is a woman, and zero otherwise. Hence, if the first author is female, the article needs to have a minimum of two female authors. ${ }^{26}$ In the second equation, (11), the dependent variable takes value one if the article is single authored and zero otherwise. In what follows, all variables included in the analysis are presented. Full definitions and sources are provided in Appendix E and summary statistics are reported in Table A1 in Appendix B.

There are three author specific variables, female, publications in top5 and affiliation to top3. Female takes the value one if the first author is a woman and zero otherwise. Publications in top5 is the publication record in top five journals between 1950 and the year of publication for the first author of the article. Affiliation to top 3 is an indicator variable taking the value one if the first author affiliated to the University of Chicago, Harvard University or MIT.

As a measure of our main explanatory variable, namely the fraction of women in the relevant population of researchers, corresponding to $\phi$ in the model, we compute an article specific mean female share. Since articles typically have more than one JELcode, we define the mean female share of the article as the weighted average of the female share in the JEL-fields of the article in the publication year, where the weights are the relative sizes of the JEL-fields in that year. The female share by JEL-field is computed as the share of female to male authors of all the articles in the JEL-field,

\footnotetext{
${ }^{25}$ In Section 4.3, we present results when all 5308 authors are included as observations. Since the qualitative results are not altered, we will focus the presentation on the specification using articles as observations.

${ }^{26}$ The dependent variable takes the value zero for all single authored articles.
} 
weighted by the number of authors of each article. The average female share of articles in each JEL-field and the sizes of fields over time are reported in Table 2 above. The construction of the article specific measure of the prevalence of single authorship, mean single share is analogous.

In addition to the measures of the mean female share and the mean single share constructed with data from our sample, we use the AEA Membership Directories for 1993, 1997 and 2002, as an independent source for the female share in the JEL-fields, and the entire EconLit as a source for the relative sizes of subfields in Economics. ${ }^{27}$ Using these alternative sources of information on size and female presence, we construct four different measures of the mean female share. For the mean single share, we only have information on the share of single authored articles from our sample.

There are two team specific indicator variables included in the main analysis. The first, local team takes the value one if at least one of the coauthors has the same affiliation as the first author and zero otherwise. The second, senior, takes the value one if the first author has a better publication record than the coauthors.

As article specific variables we use print year to control for time trends, source to capture potential differences between our three journals, and the number of pages of the article as a potential indicator of quality. We also include dummy variables for the AER Papers and Proceedings and for conference volumes in the Journal of Political Economy.

\subsection{Main results}

Table 6 reports the log-odds estimates from the probit estimation of equation (10) when only articles with two authors are included. ${ }^{28}$ The dependent variable is female team mate. The advantage of using only observations with two authors is that female team mate is then a truly binary variable. The loss of observations is relatively minor since only one fifth of the non-single authored articles have more than two authors. ${ }^{29}$ All estimations include all the article-specific controls, the article's mean single share, as well as dummy variables for each JEL-field. The parameter estimates are not reported due to space limitations.

\footnotetext{
${ }^{27}$ Linear extrapolation of the female shares by JEL-field for 1993, 1997 and 2002 has been used to obtain yearly field specific female shares. The AEA membership directory has no good measure of the size of JEL fields over time. The AEA directories contain information about the members' two main field of research. There appears however to be a strong trend in how members indicate their research interest since the beginning of the 1990s. For example, macroeconomics (E) and international economics (F) accounted in 1993 for approximately 40 percent of members' research interests, but only for 20 percent in 1997. These trends do not correspond to the development neither in our sample or in the sample of all articles in EconLit. Thus, it is most likely due to a changing norm within the profession going from indicating general research interests to more specific JEL-fields.

${ }^{28}$ Logit estimations yield very similar results, and are available from the authors upon request.

${ }^{29}$ Including all observations while controlling for multiple authorship leaves the results qualitatively unchanged, as is shown in the robustness checks in Section 4.3.
} 


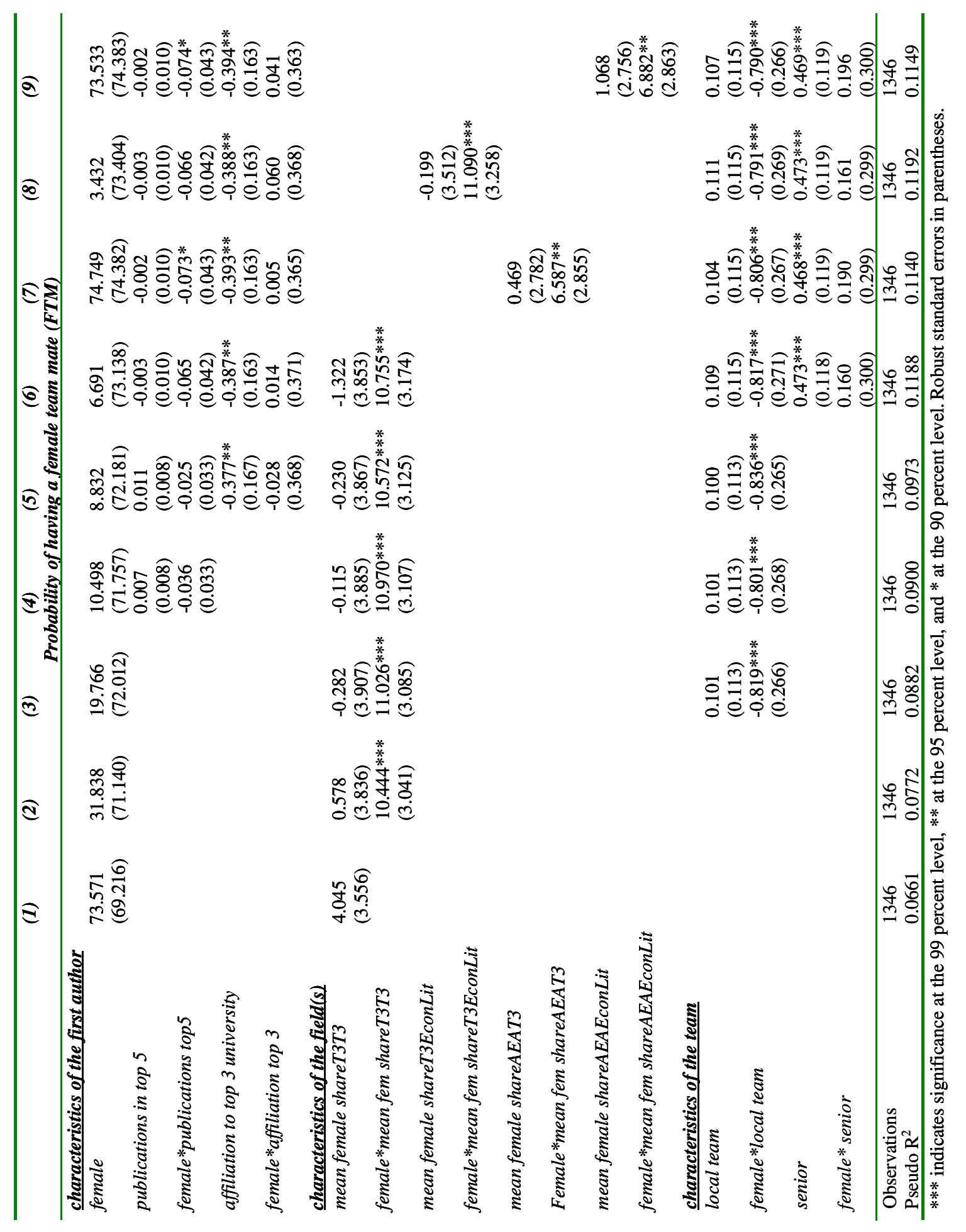

Table 6: Probit estimation results, Female team mate

Column (1) in Table 6 contains only two explanatory variables (the non-reported controls uncounted), female and mean female share. None of these are significant, 
indicating that on average women are not more likely to have a female coauthor than men are. When the interaction between female and mean female share, is included, the results change. The interaction effect is now positive and significant at the 99 percent level. Thus, as the mean female share increases, the female propensity to coauthor with a woman increases significantly more than the male propensity to coauthor with a woman. The interaction effect remains highly significant when including additional controls and also when changing the data sources of the mean female share, see Columns (7) to (9). The probability of coauthoring with a woman is significantly lower for authors affiliated to either Harvard, MIT, or the University of Chicago. For women, being part of a local team also significantly lowers the probability of coauthoring with a woman.

Computing the marginal effects in column (6) at the average mean female share (12.6 percent), an increase in the mean female share by 10 per cent, raises the female probability to coauthor with a woman by with 17 percent, while it does not significantly affect male authors.

Table 7 presents the results of probit estimations of equation (11), where single authorship is the dependent variable. The entire sample of 3090 articles is now used. In all specifications, women are more likely than men to single author. The probability of single authoring decreases as the mean female share increases. In specifications including an interaction effect between female and mean female share, female authors reduce their single authorship more as the mean female share increases. A consistent, although only weakly significant, pattern is that women affiliated to Harvard, MIT or Chicago tend to single author more than their male colleagues.

How do these results compare to the predictions of the model? The estimations of equation (10) show that the female propensity to coauthor with a woman increases more than the male propensity to coauthor with a woman as the share of female researchers increases. In terms of the model presented in Section 2, this implies that $\hat{\beta}_{m}^{F T M}<\hat{\beta}_{f}^{F T M}$. Table 8 summarizes the implications of the model when this is the case. The hypothesis of gender irrelevance is clearly not consistent with data since it does not allow for $\beta_{m}^{F T M}<\beta_{f}^{F T M}$. What about the weaker form of gender neutrality? All the specifications in Table 7 indicate that women single author more, rather than less, compared to men. Hence, we are able to reject gender neutral team formation. Even when controlling for differences across authors, fields, team and articles, gender does matter for team formation in Economics. The common idea, that economists do not coauthor with women to any significant extent because there are no women to coauthor with, is thereby incorrect. Our results in fact suggests the opposite, namely that, as the share of women increases, the gender gap in the propensity to coauthor with a women increases as well. Thus, there are no indications that gender sorting in teams automatically disappears as more women enter the profession. 


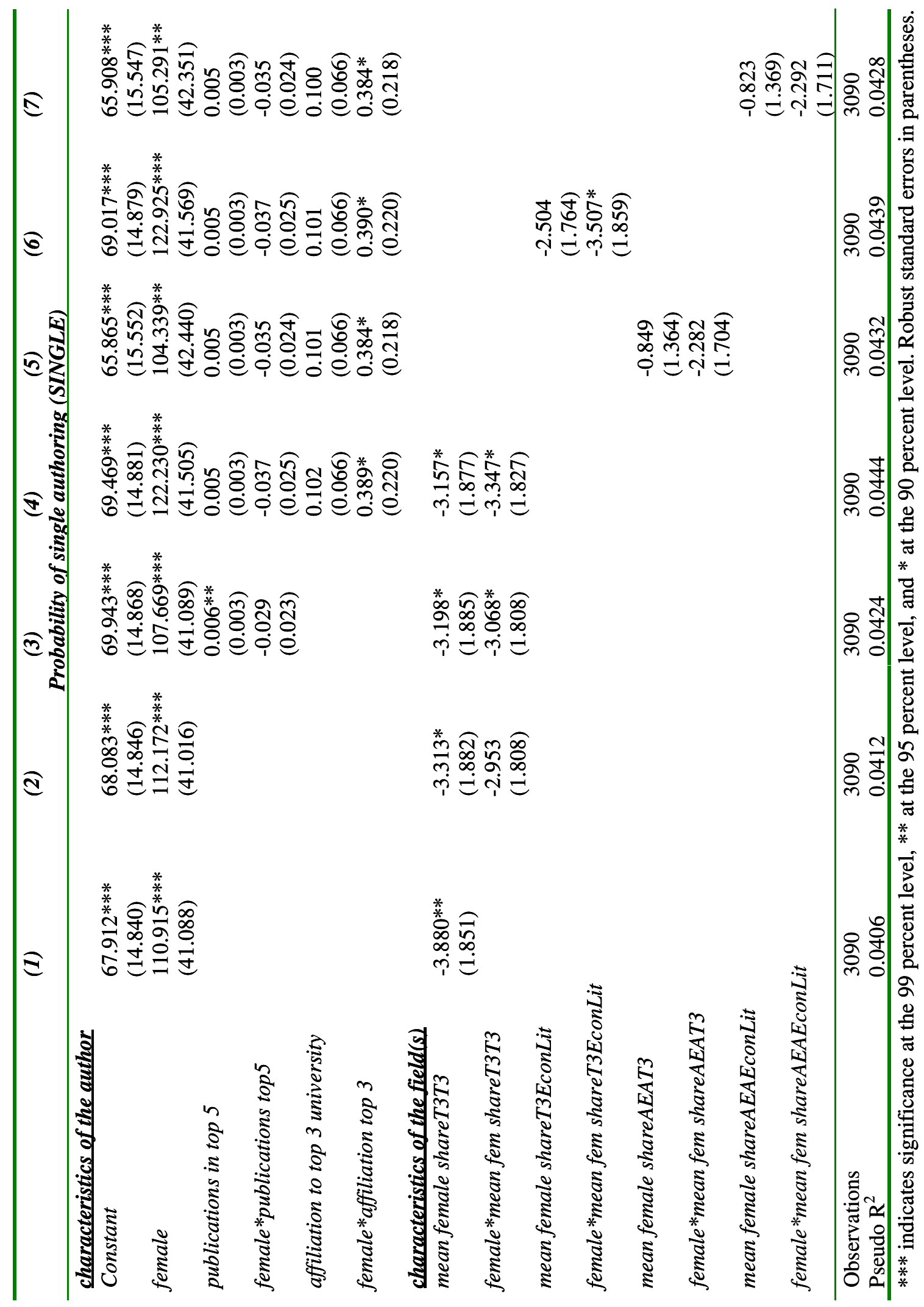

Table 7: Probit estimation results, Single authorship 


\begin{tabular}{lccc}
\hline \hline & \multicolumn{3}{c}{ Equation } \\
\cline { 3 - 4 } Hypothesis & Female team mate & Single authorship \\
\cline { 1 - 4 } Gender irrelevance & $\beta_{m}^{F T M}=\beta_{f}^{F T M}$ & $\alpha_{m}=\alpha_{f}$ & $\beta_{m}^{S}=\beta_{f}^{S}=0$ \\
Gender neutrality & $\beta_{m}^{F T M}<\beta_{f}^{F T M}$ & $\alpha_{m}>\alpha_{f}$ & $\beta_{m}^{S}<\beta_{f}^{S}$ \\
\hline \hline
\end{tabular}

\section{Table 8: The implications of the model.}

Our results are, however, based on a restrictive sample of journals. The sample has been chosen primarily to control for the quality of output of the teams formed. Arguably the coauthorship pattern found in these top journals reflects the preference rankings at least at the top of the ability distribution. Have we detected gender preferences or not? It is possible to argue that we have not if we believe that the men and women at the top have very different publication strategies. But, even if men and women were to have different cut-off quality levels for when they judge a paper good enough to send to these journals, the low level of acceptance is likely to undo any such biases, since the cut-off quality for publication is likely to exceed the cut-off quality for submission for all authors and all team types. Another concern is that what we see could be the effect of a refereeing process that discriminates against some types of teams. But, according to Blank (1991) there is no evidence of bias against any sex in the referee process of these journals.

\subsection{Robustness of the results}

This section test the robustness and stability of the main results by including additional controls, alternative measures and by varying the sample.

First, we include one new control, recurrent team. Recurrent team is a binary variable which takes the value one if an article is written by a constellation of coauthors that appears more than once in our data. Column (1) in Table 9 shows that this variable does not enter significantly.

We also test an alternative measure of author seniority. Instead of using the number of publications, we use the year of the author's first publication in top5 journals. ${ }^{30}$ As column (2) indicates, the probability of having a female coauthor increases the more recent the first publication of the author is. There are, however, no gender specific effects.

\footnotetext{
${ }^{30}$ Controlling for both measures simultaneously yields insignificant parameter estimates due to multicollinearity.
} 


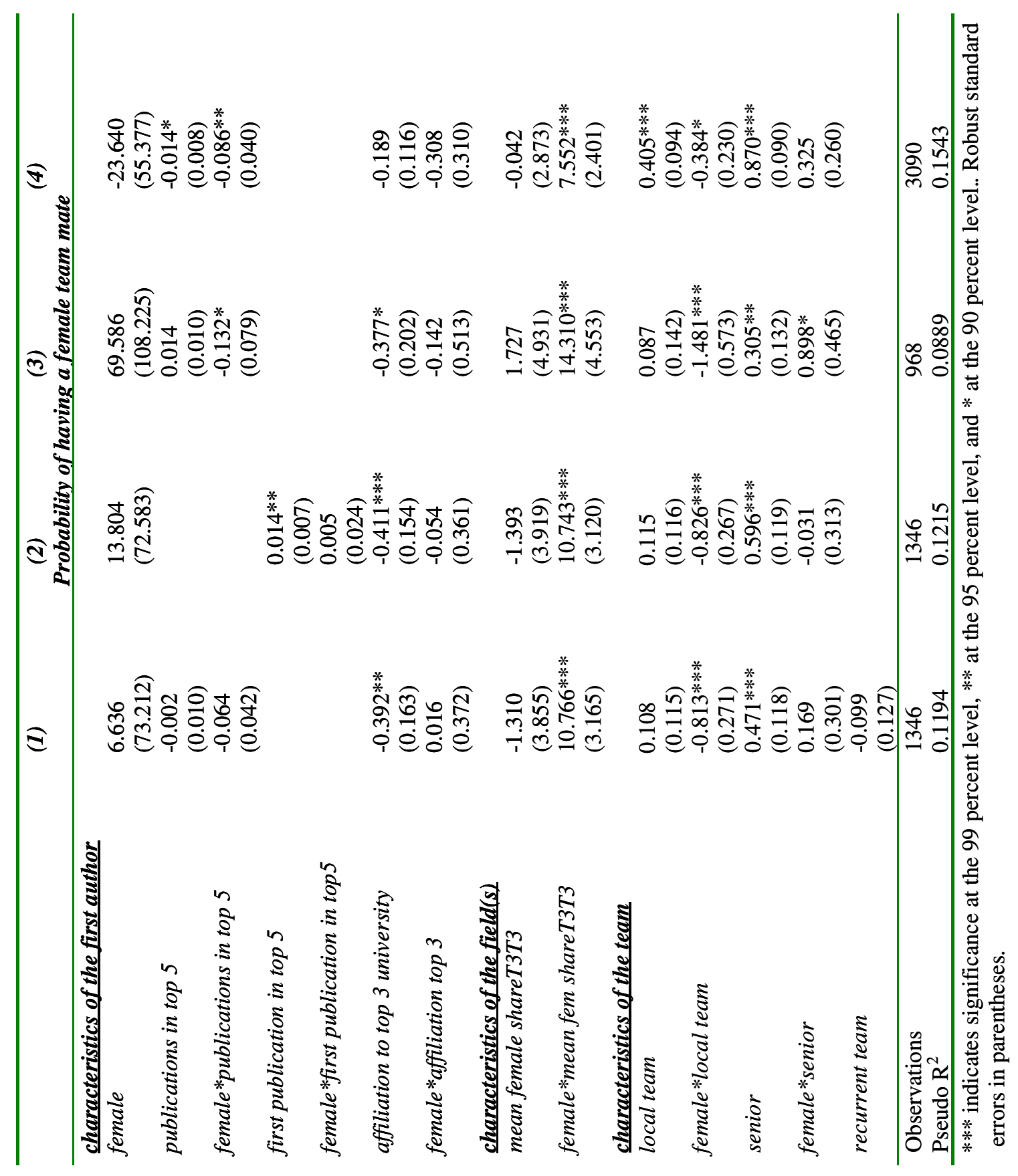

Table 9: Robustness

In columns (3) and (4) of Table 9, we investigate the effects of altering the sample. In column (3) all the observations from the American Economic Review's May number (Papers and Proceedings of the AEA meetings) are excluded together with the conference volumes of the Journal of Political Economy. The results remain qualitatively the same. If anything, the gender gap in the probability to coauthor with a woman increases slightly. Column (4) reports the results when we include all articles, i.e. single 
authored, articles with two authors as well as articles with more than two authors. A dummy for more than two authors is also included but not reported. Again, the main results are not altered. ${ }^{31}$

As a test of the stability of our result across the distribution of mean female share, we include the square and the cube of the mean female share to capture potential non-linearities, but we do not find any significant effects. As an alternative, we have investigated the effects of including dummy variables for high mean female share (higher than 12.6) as well as for the different quintiles of the mean female share distribution. We are reluctant to draw conclusions based on the results of these investigations. The estimates are for the most part insignificant and highly sensitive to the inclusion of multi- and single-authored articles, but we cannot rule out that the pattern of gender sorting may vary across the distribution. The results are not reported.

As a last robustness test, we reshape our data set and use all 5308 authors instead of the 3090 articles as our observations. Excluding single authored articles, the reshaped data set has 3955 observations. ${ }^{32}$ In this way the results do not depend on the randomizing device for the first author. Furthermore, it enables us to control for the author specific characteristics of all authors, not only of the first author. The drawback is that each article appears as many times as there are authors, and hence the observations are not independent. To handle this, we cluster the residuals on article. The results are presented in Table A4 in Appendix F. The main results hold true also when authors are the level of observation. Columns (1) to (4) differ with respect to which measure of mean female share has been used. A new result, compared to the results presented in Table 6 is that the interaction between publications in top 5 and female now is negative and significant. This could either mean that compared to male authors, women are more likely to coauthor with women when they have few publications; or, more likely, that junior female economists have a greater choice of female coauthors than senior female economists.

\section{Concluding remarks}

We have modeled the formation of teams as a random matching process influenced by the team members' preferences for team size and gender of team mates. We have then tested a set of hypotheses on the distributions of gender and team preferences on the pattern of authorships in articles published 1991-2002 in three top Economics journals.

\footnotetext{
${ }^{31}$ We have tried other alternative variables, three of which are particularly worth mentioning. First, as yet another measure of the mean female share we have constructed yet an article-specific mean female share. This is calculated by excluding the article in question when computing the mean female share for the articles in our sample. The results using this article-specific mean female share are both qualitatively and quantitatively close to identical to the mean female share (T3T3) used. Second, we have tested whether other measures of affiliation, such as affiliation to one of the US top20 universities or being a NBER member significantly affects the propensity of having a female coauthor. They do not.

${ }^{32}$ Estimating the probability of single authorship is inappropriate in this data set, since single authored articles only show up once, while coauthored articles appear at least twice. This problem is not adequately solved by clustering the observations by articles.
} 
We find that the female-male gap in the propensity to coauthor with a woman increases with the presence of women in the field of research. This, together with the finding that women single author significantly more than men, allows us to reject hypotheses of gender irrelevance as well as gender neutrality. Both robustness checks and the calibration of the model using realistic parameter values confirm that the pattern in the data is incompatible with gender neutrality. We can therefore conclude that there is indeed evidence of gender sorting in team formation. Our results show, counter to the common notion, that the relative lack of gender mixed teams in Economics will not automatically disappear as the pool of potential women coauthors increases.

At a more general level, gender sorting in team formation driven by some form of gendered preferences may be part of the explanation for why we observe persistent gender segregation on the labor market. Our findings suggest that gender segregation may be linked to the prevalence of teamwork. However, while academia, and Economics in particular, is excellent for studying team formation since team formation is voluntary and productivity easily measured, there are at most 22 percent women in any of the major subfields of Economics. What happens to gender preferences as the share of women increases beyond this level is consequently somewhat speculative. There may for instance be learning effects.

The main contribution of our paper is that we have established that there is gender sorting in team formation also at the field level in Economics. We can conclude that the observed gender pattern in team formation is not due to gender sorting into fields or to differences in returns to coauthorship across fields, nor does it seem to be driven by gender differences in affiliations or seniority. It remains the task of future research to uncover the driving forces of gender sorting in team formation and determine to what extent they are taste based or productivity based.

\section{References}

[1] The Annual Report of the Commission on the Status of Women in the Economics Profession, American Economic Review: Papers and Proceedings, several issues.

[2] Becker, Gary S., and Kevin M. Murphy, (1992), "The Division of Labor, Coordination Costs, and Knowledge", The Quarterly Journal of Economics, Vol. CVII, No. 4. pp. 1137-1160.

[3] Blanck, Rebecca M., (1991), "The Effects of Double-Blind versus Single-Blind Reviewing: Experimental Evidence from the American Economic Review." The American Economic Review, Vol. 81, No. 5, pp. 1041-1067.

[4] Breen, Richard and García-Peñalosa, Cecília, (2002), "Bayesian Learning and Gender Segregation" Journal of Labor Economics, Vol. 20, No. 4, pp. 899-922. 
[5] Dolado, Juan J, Florentino Felgueroso and Miguel Almunia (2005), "Do Men and Women Economists Choose the Same Research Fields?: Evidence from Top 50 Departments", CERP Discussion Paper Series No 5421.

[6] Ferber, Marianne A. and Michelle Teiman, (1980), "Are Women Economists at a Disadvantage in Publishing Journal Articles?", Eastern Economic Journal, Vol. VI, Nos 3-4.

[7] Ginther, Donna K., and Shulamit Kahn, 2004, "Women in Economics: Moving Up or Falling Off the Academic Career Ladder", Journal of Economic Perspectives, Vol. 18, No. 3, pp. 193-214.

[8] Goyal, Sanjeev, Marco van der Leij and José Luis Moraga-Gonzáles, (2004), "Economics: an emerging small world?", Journal of Political Economy, forthcoming.

[9] Hamermesh, Daniel S. (2004), "An Old Male Economist's Advice to Young Female Economists". mimeo.

[10] Hamermesh, Daniel S. and S. M. Oster, (2002), "Tools or Toys? The Impact of High Technology on Scholarly Productivity", Economic Inquiry, Vol. 40, No. 5, pp. 539-555.

[11] Ivanova-Stenzel, Radosveta, and Dorotea Kübler, (2005), "Courtesy and Idleness: Gender Differences in Team Work and Team Competition", IZA DPS No. 1768.

[12] Kahn, Shulamit, (1995), "Women in the Economics Profession", Journal of Economic Perspectives, Vol. 9, No. 4, pp. 193-205.

[13] Kahn, Shulamit, (2002), "The Status of Women in Economics during the Nineties: One step forward, Two steps back", Paper presented at AEA Meetings in Atlanta 2002.

[14] Kandel, Eugene and Edward P. Lazear, (1992), "Peer Pressure and Partnership", Journal of Political Economy, Vol. 100, No. 4, pp. 801-817.

[15] Laband, D. N. and R. D. Tollison, (2000), "Intellectual Collaboration", Journal of Political Economy, Vol. 108, No. 3, pp. 632-662.

[16] McDowell, John and Janet Kiholm Smith, (1992), "The effect of gender-sorting on propensity to coauthor: implications for academic promotion", Economic Inquiry, Vol. 30, pp. 68-82.

[17] McDowell, John M., Larry D. Jr Singell and James P. Ziliac, (1999), "Cracks in the Glass Ceiling : Gender and Promotion in the Economics Profession." American Economic Review, Papers and Proceedings, Vol. 89, No.2, pp. 392-396.

[18] McDowell, John M., Larry D. Jr Singell and James P. Ziliac (2001). "Gender and Promotion in the Economics Profession." Industrial and Labor Relations Review, Vol. 54, No. 2. 
[19] Prat, Andrea, (2002) "Should a Team Be Homogeneous?" European Economic Review, Vol. 46, No. 7, pp. 1187-1207.

[20] Sauer, R. D., (1988), "Estimates of the Returns to Quality and Coauthorship in Economic Academia", Journal of Political Economy, Vol. 96, No. 4, pp. 855-866.

\section{A Proofs of propositions 1 and 2}

\section{Proposition 1}

Proof. If $\sigma_{f}=\sigma_{m}=\sigma, \mu_{f}=\mu_{m}=\mu, \kappa_{m}=\kappa_{f}=\kappa$ and $\nu_{f}=\nu_{m}=1$, then $P(F T M \mid i)=(1-\sigma)^{2} \phi$, and $P(S \mid i)=1-(1-\sigma)^{2}$ for $i=m, f$.

\section{Proposition 2}

Proof. If $\nu_{f}=\nu_{m}=1$,

$$
\begin{array}{r|l}
P(F T M & m)=\left(1-\sigma_{f}\right)\left(1-\sigma_{m}\right) \phi \\
P(F T M & f)=\left(1-\sigma_{f}\right)^{2} \phi \\
P(S & m)=1-\left(1-\sigma_{m}\right)^{2}+\left(1-\sigma_{m}\right)\left(\sigma_{f}-\sigma_{m}\right) \phi \\
P(S & f)=1-\left(1-\sigma_{f}\right)\left(1-\sigma_{m}\right)+\left(1-\sigma_{f}\right)\left(\sigma_{f}-\sigma_{m}\right) \phi .
\end{array}
$$

Hence if $\sigma_{m} \gtreqless \sigma_{f}$ it follows that $\beta_{m}^{F T M} \lesseqgtr \beta_{f}^{F T M}, \alpha_{m} \gtreqless \alpha_{f}$, and $\beta_{m}^{S} \lesseqgtr \beta_{f}^{S}$. 


\section{B Summary statistics}

\begin{tabular}{lrrrrr}
\hline \hline & \multicolumn{5}{c}{ Summary statistics } \\
\cline { 2 - 6 } Variable & & Mean & Std. Dev. & Min & Max \\
properties of the team & & & & & \\
number of authors & 3090 & 1.72 & 0.76 & 1 & 8 \\
female share of authors & 3090 & 0.12 & 0.29 & 0 & 1 \\
mixed team & 3090 & 0.11 & 0.31 & 0 & 1 \\
single authored & 3090 & 0.44 & 0.50 & 0 & 1 \\
local team & 3090 & 0.19 & 0.39 & 0 & 1 \\
& & & & & \\
properties of the first author & & & & & \\
female & 3090 & 0.13 & 0.34 & 0 & 1 \\
publication record in top 5 & 3090 & 5.19 & 8.02 & 0 & 65 \\
first top 5 publication & 3090 & 1987.11 & 10.77 & 1950 & 2002 \\
properties of the article & & & & & \\
print year & 3090 & 1996.25 & 3.46 & 1991 & 2002 \\
number of pages & 3090 & 15.91 & 12.23 & 1 & 96 \\
JPE & 3090 & 0.19 & 0.40 & 0 & 1 \\
QJE & 3090 & 0.17 & 0.37 & 0 & 1 \\
& & & & & \\
D-microeconomics & 3090 & 0.27 & 0.44 & 0 & 1 \\
E-Macroeconomics & 3090 & 0.16 & 0.36 & 0 & 1 \\
F-International Economics & 3090 & 0.10 & 0.31 & 0 & 1 \\
G-Financial Economics & 3090 & 0.10 & 0.30 & 0 & 1 \\
H-Public Economics & 3090 & 0.09 & 0.29 & 0 & 1 \\
I-Health, Education and Welfare & 3090 & 0.08 & 0.27 & 0 & 1 \\
J-Labor and Demographic Economics & 3090 & 0.22 & 0.41 & 0 & 1 \\
L.Industrial Organization & 3090 & 0.12 & 0.32 & 0 & 1 \\
O-Economic Development and Growth & 3090 & 0.14 & 0.35 & 0 & 1 \\
ZZ-other & 3090 & 0.11 & 0.31 & 0 & 1 \\
properties of the field(s) of the article & & & & & \\
mean female share (T3T3) & 3090 & 0.13 & 0.04 & 0.08 & 0.21 \\
mean female share (T3EconLit) & 3090 & 0.13 & 0.04 & 0.08 & 0.21 \\
mean female share (AEAT3) & 3090 & 0.14 & 0.04 & 0.08 & 0.26 \\
mean female share (AEAEconLit) & 3090 & 0.14 & 0.04 & 0.08 & 0.26 \\
mean single share (T3T3) & 3090 & 0.42 & 0.06 & 0.27 & 0.54 \\
mean single share (T3EconLit) & 3090 & 0.42 & 0.06 & 0.27 & 0.54 \\
mean single share in print year (T3T3) & 3090 & 0.43 & 0.12 & 0.10 & 0.82 \\
mean single share in print year (T3EconLit) & 3090 & 0.43 & 0.12 & 0.10 & 0.82 \\
\hline \hline & & & & &
\end{tabular}

Table A1: Summary Statistics 


\section{EconLit classification}

The JEL-codes used in the analysis are those provided by EconLit. These are not necessarily the same as those given by the authors. The reason for using the EconLit JEL-codes is that the articles published in the Journal of Political Economy do not have JEL-codes. A further argument is that the EconLit employs independent classifiers to assign JEL-codes and key words to all articles. This makes the EconLit JEL-codes more likely to be more consistent than JEL-codes assigned by the authors themselves.

"We have no manual on classifications. Our classifiers (graduate and doctoral students of Economics), memorize the classification as they begin to use it. Their classifications are checked, and their misclassifications are discussed with them. The person in charge of classification (a University Professor of Economics) uses this method to maintain a high degree of consistency (although it can never be perfect). Economics is such a conceptual subject that differences in opinion are common. We try to classify articles under the subject descriptors (up to seven) where we think an economist would look to find such an article. We try to classify articles under the subject matter, not the theory (such as macroeconomics subdivisions). We put articles under the C, D, and E categories when the subject is the theory." [personal communication with employee at EconLit]

\section{C.1 The JEL-classification codes}

A - General Economics and Teaching

B - Schools of Economic Thought and Methodology

C - Mathematical and Quantitative Methods

D - Microeconomics

E - Macroeconomics and Monetary Economics

F - International Economics

G - Financial Economics

$\mathrm{H}$ - Public Economics

I - Health, Education, and Welfare

$\mathrm{J}$ - Labor and Demographic Economics

$\mathrm{K}$ - Law and Economics

L - Industrial Organization

M - Business Administration and Business Economics; Marketing; Accounting

$\mathrm{N}$ - Economic History

O - Economic Development, Technological Change, and Growth

$\mathrm{P}$ - Economic Systems

Q - Agricultural and Natural Resource Economics

R - Urban, Rural, and Regional Economics

Z - Other Special Topics 


\section{AEA membership directories}

In order to obtain an independent source for the share of female researchers in the different sub-fields of Economics, we have used the American Economic Association membership directory. The AEA membership directory is only available for three years during the period between 1991 and 2002, namely 1993, 1997 and 2002. The directories contain self-reported information on main fields of interest, educational background, current position and optional information on gender and race. These data are collected upon registration.

\begin{tabular}{|c|c|c|c|c|c|}
\hline \multirow[b]{2}{*}{$\begin{array}{l}\text { AEA Directory and } \\
\text { coding method }\end{array}$} & \multicolumn{4}{|c|}{ Gender-coded members } & \multirow[t]{2}{*}{$\begin{array}{c}\text { Total number } \\
\text { of members }\end{array}$} \\
\hline & female & male & all coded & $\begin{array}{l}\text { as } \% \text { of all } \\
\text { members }\end{array}$ & \\
\hline 1993 Member coding & 1411 & 10166 & 11577 & 71 & 16383 \\
\hline row $\%$ & 12 & 88 & 100 & & \\
\hline 1993 Member coding + US Census & 2204 & 12824 & 15028 & 92 & \\
\hline row $\%$ & 15 & 85 & 100 & & \\
\hline 1997 Member coding & 2263 & 14424 & 16687 & 75 & 22376 \\
\hline row $\%$ & 14 & 86 & 100 & & \\
\hline 1997 Member coding + US Census & 3249 & 17728 & 20977 & 94 & \\
\hline row $\%$ & 15 & 85 & 100 & & \\
\hline 2002 Member coding & 1301 & 9777 & 11078 & 51 & 21928 \\
\hline row $\%$ & 12 & 88 & 100 & & \\
\hline 2002 Member coding + US Census & 3230 & 16062 & 19292 & 88 & \\
\hline row $\%$ & 17 & 83 & 100 & & \\
\hline
\end{tabular}

Table A2: Gender coding AEA-directories

In the 1993 and 1997 directories, gender is missing for 25 to 30 percent of the members. The 2002 membership directory unfortunately does not contain any gender information, as this was removed by the firm administrating the directory. We have gender-coded the missing information by using the United States Census Bureau's list of the most common names. From these lists, containing 1219 male and 4275 female names, we have computed the probability that the holder of any particular name is male or female. ${ }^{33}$ We have matched this list to the AEA membership directory and thereby considerably improved our fraction of gender-coded AEA members not only for year 2002 but also for 1993 and 1997, see Table A2. For year 2002, which is the most problematic year in terms of missing gender information, this procedure implied

\footnotetext{
${ }^{33}$ After the 1990 United States Census, an independent post-Census operation (the 1990 PostEnumeration Survey-PES) collected information about names and sex. The PES provides lists of male and female names and frequencies, covering $90 \%$ of the population. More information about frequent first names and methodology is available at http://www.census.gov/genealogy/names/.
} 
passing from having gender information only for old members (constituting 51 percent of the 2002 members), to successfully gender coding 88 percent of the members. Table A2 reveals that women are somewhat more reluctant than men to state their gender in the AEA membership directory. 


\section{E Definition of variables}

\begin{tabular}{|c|c|c|}
\hline Variable & Definition & Source \\
\hline \multicolumn{3}{|c|}{ Characteristics of the first author } \\
\hline Publications in top5 & $\begin{array}{l}\text { author's number of publications in American Economic } \\
\text { Review, Econometrica, Journal of Political Economy, } \\
\text { Quarterly Journal of Economics, and Review of Economic } \\
\text { Studies from } 1950 \text { until the year of publication of the article } \\
\text { in our sample }\end{array}$ & JSTOR \\
\hline $\begin{array}{l}\text { First publication in } \\
\text { top5 }\end{array}$ & $\begin{array}{l}\text { year of the author's first publication in American Economic } \\
\text { Review, Econometrica, Journal of Political Economy, } \\
\text { Quarterly Journal of Economics, or Review of Economic } \\
\text { Studies from } 1950 \text { onwards }\end{array}$ & JSTOR \\
\hline $\begin{array}{l}\text { Affiliation to top } 3 \\
\text { university }\end{array}$ & $\begin{array}{l}\text { dummy if first author is affiliated to Harvard, MIT or Chicago } \\
\text { University }\end{array}$ & Own coding in T3 sample \\
\hline \multicolumn{3}{|c|}{ Characteristics of the field(s) of the article } \\
\hline $\begin{array}{l}\text { mean female share } \\
\text { (T3T3) }\end{array}$ & $\begin{array}{l}\text { the weighted average of the female share in the JEL fields of } \\
\text { the article, where the weights are the relative sizes of the JEL } \\
\text { fields in each year. The female share by JEL field is computed } \\
\text { as the share of female to male authors of all the articles in a } \\
\text { JEL field weighted by the number of authors of each article. }\end{array}$ & $\begin{array}{l}\text { Based on T3 both for the } \\
\text { female share, and for the } \\
\text { annual size of each JEL } \\
\text { field }\end{array}$ \\
\hline $\begin{array}{l}\text { mean female share } \\
\text { (T3EconLit) }\end{array}$ & as above & $\begin{array}{l}\text { Female share: T3, Annual } \\
\text { sizes of JEL-fields: all } \\
\text { articles in EconLit }\end{array}$ \\
\hline $\begin{array}{l}\text { mean female share } \\
\text { (AEAT3) }\end{array}$ & $\begin{array}{l}\text { as above, but annual female shares by fields are used. These } \\
\text { are obtained by linear extrapolation from the point estimates } \\
\text { obtained from the } 1993,1997 \text { and } 2002 \text { registers. }\end{array}$ & $\begin{array}{l}\text { Yearly female share: } \\
\text { AEA membership } \\
\text { directories; annual sizes } \\
\text { of each JEL-field: T3. }\end{array}$ \\
\hline $\begin{array}{l}\text { mean female share } \\
\text { (AEAEconLit) }\end{array}$ & as above & $\begin{array}{l}\text { Yearly female share: } \\
\text { AEA membership } \\
\text { directories;annual size of } \\
\text { JEL-fields: all articles in } \\
\text { EconLit }\end{array}$ \\
\hline $\begin{array}{l}\text { mean single share } \\
\text { (T3T3) }\end{array}$ & $\begin{array}{l}\text { the weighted average of the annual share of single authorship } \\
\text { of the JEL-fields of the article, where the weights are the } \\
\text { relative sizes of the JEL fields in each year. }\end{array}$ & T3 \\
\hline $\begin{array}{l}\text { mean single share } \\
\text { (T3EconLit) }\end{array}$ & as above & $\begin{array}{l}\text { Yearly single share: T3; } \\
\text { size of JEL-field: all } \\
\text { articles in EconLit }\end{array}$ \\
\hline \multicolumn{3}{|c|}{ Team characteristics } \\
\hline local team & $\begin{array}{l}\text { dummy that equals } 1 \text { if one coauthor has the same affiliation } \\
\text { as the first author }\end{array}$ & T3 \\
\hline senior & $\begin{array}{l}\text { dummy that equals } 1 \text { if the first author has more publications } \\
\text { than her coauthors }\end{array}$ & Based on JSTOR \\
\hline recurrent team & $\begin{array}{l}\text { Dummy that equals } 1 \text { if the same constellation of authors } \\
\text { appears at least twice in T3 }\end{array}$ & T3 \\
\hline \multicolumn{3}{|c|}{ Characteristics of the article } \\
\hline publication year & year the article is published & T3 \\
\hline number of pages & number of pages of the article & T3t \\
\hline journal & dummy for the journal in which the article is published & T3 \\
\hline
\end{tabular}

Table A3: Variable definitions and sources. 


\section{F Results when authors are observations}

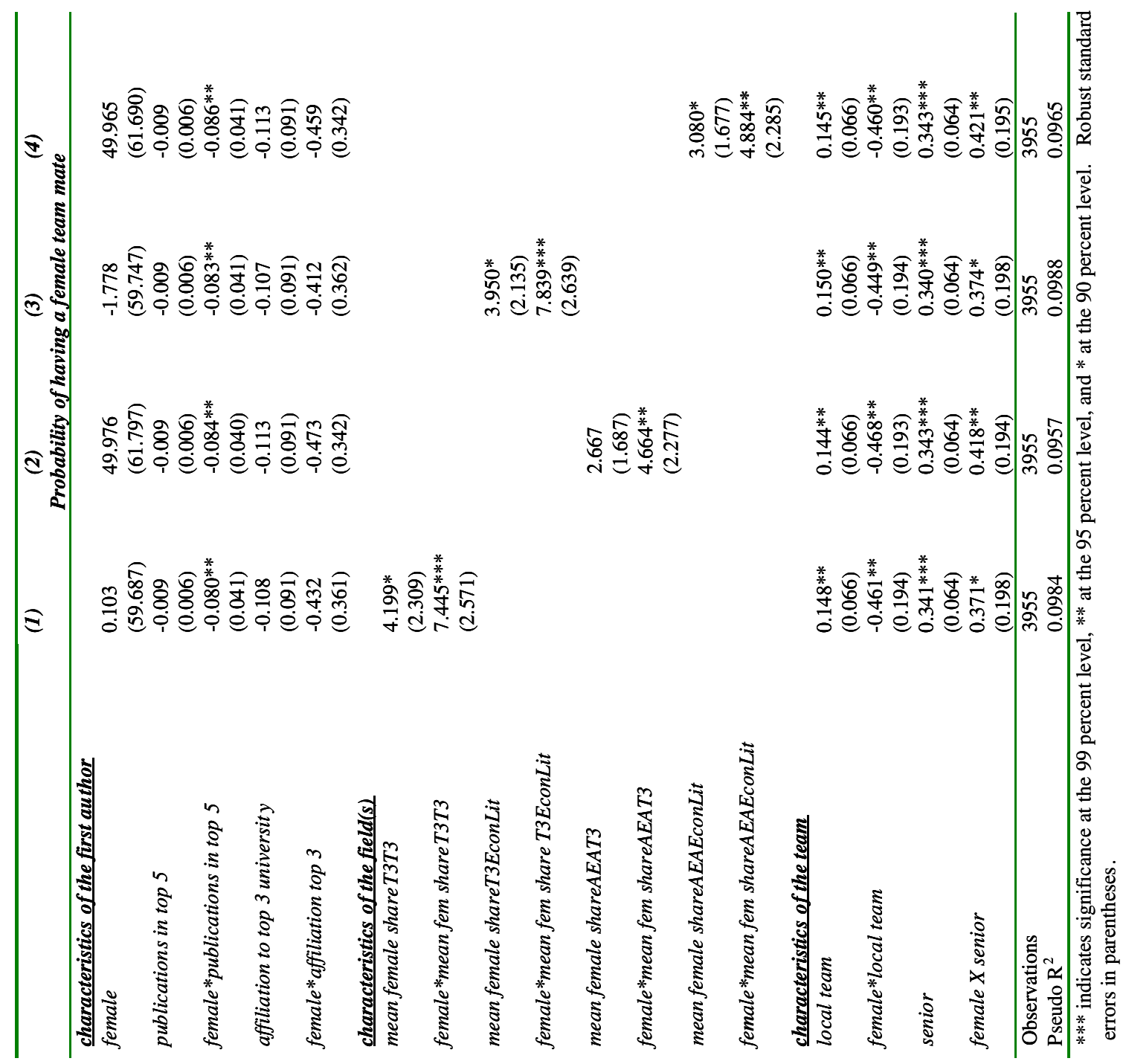

Table A4: Estimation results with author sample 